\title{
Secular trend in length of hospital stay for healthy newborns: 1951-2000
}

\author{
Mônica Barthelson C. de Moura, ${ }^{1}$ Maria Aparecida Brenelli-Vitali, ${ }^{2}$ \\ Sérgio T. M. Marba ${ }^{3}$
}

\begin{abstract}
Objective: To assess the secular trend in length of hospital stay for healthy newborns with birth weight $\geq 2,500 \mathrm{~g}$ in a large maternity hospital of Campinas, state of São Paulo, Brazil.

Methods: In this descriptive, analytical, retrospective study, data were collected from 5,001 live births from 1951 to 2000 . Studied variables were length of hospital stay, birth weight, maternal age, type of delivery, and category of admission. Linear regression analysis was used, with least squares estimation.

Results: The annual mean length of stay decreased along the period assessed: 123 hours in 1951 and 67.2 hours in 2000. Segmented linear regression analysis revealed a significant decreasing trend between 1951 and 1970, a stable period between 1971 and 1990, and a non-significant increase between 1991 and 2000. Length of hospital stay varied significantly according to type of delivery.
\end{abstract}

Conclusion: Length of hospital stay decreased significantly between 1951 and 2000 and was influenced by type of delivery only.

J Pediatr (Rio J). 2009;85(2):175-178: Newborn, length of hospital stay, hospitalization.

\section{Introduction}

For the last decades, it has been largely accepted that deliveries should be carried out in a hospital environment, for the safety of both the mother and the newborn. Many women, however, either want or are encouraged to go home earlier than recommended, and as a result, the length of hospital stay for both mother and child has decreased. ${ }^{1,2}$

In the United States, during the 1940s, the length of hospital stay for normal newborns was around 7 to 10 days. ${ }^{3}$ During the 1960s and 1970s, economic and social factors motivated a decreasing trend in that length. ${ }^{4}$ Due to the great dissatisfaction of women and health professionals with hospital protocols, changes were made to the legislations as of 1995 and 1998, guaranteeing coverage of all costs related to hospital stay for a minimum of 48 and 96 hours following vaginal and cesarean deliveries, respectively. ${ }^{5}$ In Brazil, although no studies have been published on the topic, the Brazilian Ministry of Health determined, in September 1993, that normal newborns should not be discharged before 48 hours. $^{6}$

The objective of this study was to assess the secular trend in length of hospital stay for healthy newborns in a large maternity hospital, so as to provide support for infant health care planning.

\section{Methods}

In this descriptive, analytical, retrospective study, data were collected from hospital records of all live births from January 1, 1951, to December 31, 2000, in a large maternity hospital of Campinas, state of São Paulo, Brazil. All children

1. Mestre. Departamento de Pediatria, Faculdade de Ciências Médicas, Universidade Estadual de Campinas (UNICAMP), Campinas, SP, Brazil.

2. Doutora. Departamento de Pediatria, Faculdade de Ciências Médicas, UNICAMP, Campinas, SP, Brazil.

3. Doutor. Professor assistente, Departamento de Pediatria, Faculdade de Ciências Médicas, UNICAMP, Campinas, SP, Brazil. Diretor, Divisão de Neonatologia, Centro de Atenção Integral à Saúde da Mulher, UNICAMP, Campinas, SP, Brazil.

No conflicts of interest declared concerning the publication of this article.

Suggested citation: de Moura MB, Brenelli-Vitali MA, Marba ST. Secular trend in length of hospital stay for healthy newborns: 1951-2000. J Pediatr (Rio J). 2009;85(2):175-178.

Manuscript received Feb 28 2008, accepted for publication Aug 202008.

doi:10.2223/JPED. 1887 
weighing $\geq 2.500 \mathrm{~g}$ were included; cases of multiple pregnancy, cases presenting clinical complications and children left for adoption were excluded.

Sample size was defined based on the length of hospital stay observed for 10 randomly selected cases/year. The mean length of stay was calculated for 5 -year periods; the analysis of differences between mean lengths resulted in a sample size of 5,001 records (100 subjects/year). The Epi-Info software was used to draw records for inclusion in the study. For each year, a table was built with 1,095 or 1,098 numbers, representing days (365 or 366 for leap years) and three different time periods, as follows: 0:00 a.m. to 7:59 a.m., 8:00 a.m. to 03:59 p.m., and 04:00 p.m. to 11:59 p.m. Each drawn number corresponded to a newborn that was identified in the birth records based on time period, day, month and year of birth. The first newborn in each period was first considered for inclusion in the study; whenever the first newborn did not match the inclusion criteria, the following eligible newborn was selected.

The dependent variable in the present analysis was length of hospital stay, defined as the time, in full hours, elapsed from birth to discharge. When the exact time of discharge was not available, the period of discharge was taken into consideration: for patients discharged in the morning, the time was assumed to be 10:00 a.m.; for patients discharged in the afternoon, the time was assumed to be 03:00 p.m. The independent variables were birth weight, maternal age, type of delivery, and category of admission, depending on the financing agent responsible for hospitalization.

In order to analyze the secular trend in length of hospital stay according to year of birth, linear regression analysis with least squares estimation was employed. The analysis was carried out both for the whole group and for each independent variable. Significance was set at $5 \%$.

\section{Results}

The number of live births in the hospital from 1958 to 2000 was 333,656; no data were available for years before 1958 .

Table 1 shows the frequency of categorical variables and descriptive statistical results for the continuous variables assessed. Length of hospital stay (mean $=74.2$ hours) was extremely variable, and the assessment of year means revealed a clear decrease in the 50 years analyzed.

The secular trend in mean length of hospital stay was calculated using segmented linear regression in order to assess different year intervals: 1951-1970, 1971-1990, and 1991-2000. Figure 1 shows a significant decreasing trend in length of stay from 1951 to 1970 , at 3.66 hours per year. From 1971 to 1999 , the decreasing trend was not observed, and the mean length remained around 60.3 hours. As of 1991, a change can be observed in the curve, with a slight increasing trend in length of stay, although with no statistical significance.
In the hospital stay analysis according to birth weight, maternal age, category of admission and type of delivery, a significant difference was observed only in relation to type of delivery in the studied period ( $p<0.01$ ). From 1951 to 1970 , both cesarean and vaginal deliveries presented significant decreasing trends in length of hospital stay, with a more pronounced decrease associated with surgical deliveries. From 1971 to 2000 , only cesarean deliveries showed a statistically significant decrease.

\section{Conclusion}

The maternity hospital investigated in the present study operates since 1913. It is a public, philanthropic institution responsible for a large number of deliveries in the city of Campinas. The profile of the population served by the hospital is very similar to that of the general population of the city, ${ }^{7}$ which suggests that the results presented in this work may probably be generalized to the city as a whole. It is also worth noting that this is the only known study to explore such a topic in Brazilian maternities.

For the last 5 decades, there has been a significant decrease in length of hospital stay for healthy newborns. If we consider the early 1950s, we will see that the mean length was about 5 days; in the early 1970s, both mother and child were discharged no longer than 2.5 days after delivery. This means a $50 \%$ decrease in length of hospital stay in a period of 25 years.

The decrease is relatable to a trend revealed by studies carried out in other continents, ${ }^{8}$ although in those cases the trend was observed 2 decades before. Official data ${ }^{9}$ show that in 1970 , the mean length of hospital stay for deliveries in the United States was 4.1 days, compared to the 2.3 days in our study for the same year. That country reduced the length of stay in $37 \%$ from 1970 to 1992 , reaching 2.7 days ${ }^{10}$; our maternity, on the other hand, maintained a mean of 2.5 days during the 1970 s and 1980 s, despite the great decrease observed in the 2 preceding decades (1950s and 1960s).

In this study, there was no interference of birth weight with length of hospital stay, which leads us to believe that the decision to discharge newborns with birth weight $<3,000 \mathrm{~g}$ was not based on clinical issues related to this factor. Also, the type of health insurance did not influence discharges at our hospital, which may be justified by the fact that the changes made to this sector started mainly during the 1980 s, i.e., they did not occur simultaneously to the dramatic decreases observed. ${ }^{11}$ Reasonable justifications for the decrease in length of stay associated with cesarean deliveries are the higher safety of surgical procedures and, especially, the $42.8 \%$ increase in this type of delivery from 1951 to 1970.

On the other hand, an insufficient number of beds at the maternity assessed, in contrast with an increasing birth rate, could, at least in theory, explain the $50 \%$ decrease in length of hospital stay observed from 1950 to 1970 . The population 
Table 1 - Characteristics of 5,001 healthy newborns with birth weight $\geq 2,500 \mathrm{~g}$ (Campinas, Brazil, 1951-2000)

\begin{tabular}{|c|c|c|c|c|}
\hline Variable & Frequency & $\%$ & Mean \pm SD & Median \\
\hline Birth weight (g) & & & $3,270.71 \pm 415.69$ & 3,240 \\
\hline $2,500-2,999$ & 1,352 & 27.0 & & \\
\hline $3,000-3,499$ & 2,218 & 44.4 & & \\
\hline $3,500-3,999$ & 1,155 & 23.1 & & \\
\hline$\geq 4,000$ & 276 & 5.5 & & \\
\hline \multicolumn{5}{|l|}{ Type of delivery } \\
\hline Vaginal & 3,511 & 70.2 & & \\
\hline Cesarean & 1,490 & 29.8 & & \\
\hline Maternal age (years) & & & $25.61 \pm 6.05$ & 25 \\
\hline$<20$ & 770 & 15.4 & & \\
\hline $20-24$ & 1,681 & 33.6 & & \\
\hline $25-29$ & 1,343 & 26.9 & & \\
\hline$\geq 30$ & 1,207 & 24.1 & & \\
\hline \multicolumn{5}{|l|}{ Category of admission } \\
\hline Non-paying/SUS & 3,936 & 78.7 & & \\
\hline Insurance & 879 & 17.6 & & \\
\hline Private & 186 & 3.7 & & \\
\hline $\begin{array}{l}\text { Length of hospital stay } \\
\text { (hours) }\end{array}$ & & & $74.2 \pm 32.06$ & 66.25 \\
\hline$<24$ & 10 & 0.2 & & \\
\hline $24<48$ & 985 & 19.7 & & \\
\hline $48<72$ & 1,887 & 37.7 & & \\
\hline $72<96$ & 1,043 & 20.9 & & \\
\hline $96<120$ & 579 & 11.6 & & \\
\hline$\geq 120$ & 497 & 9.9 & & \\
\hline
\end{tabular}

SD = standard deviation; SUS = Brazilian public Unified Health System.

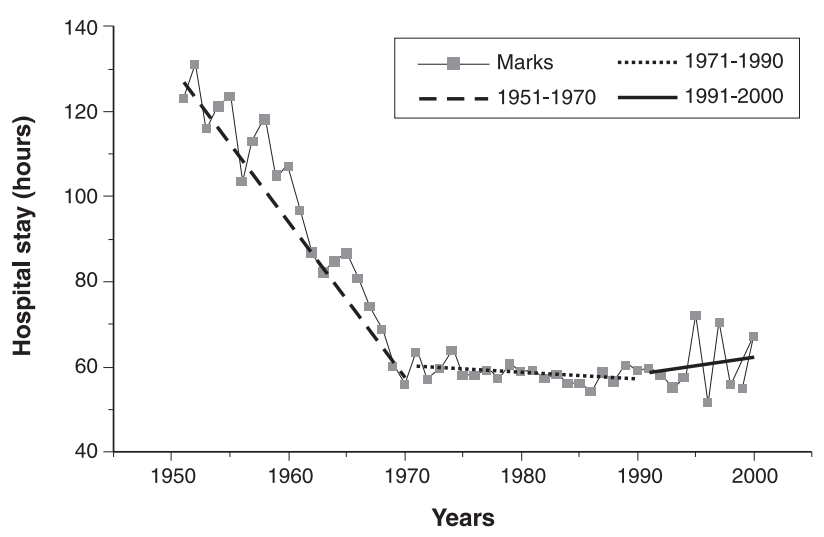

Figure 1 - Secular trend in length of hospital stay according to segmented regression model in newborns with birth weight $\geq 2,500 \mathrm{~g}$ (Campinas, Brazil, 1951-2000) of Campinas grew from 152,547 inhabitants in 1950 to 217,219 in 1960 , a $42.2 \%$ growth in 1 decade. The number of live births totaled 4,238 in 1950 and 7,109 in 1960, reflecting a birth rate of 27.28 and 32.73 , respectively. ${ }^{12}$ It is likely that the number of beds available was not enough for all births, and the early discharge of healthy newborns and their mothers possibly arose as a solution. However, other studies are necessary to fully understand this trend, focusing on the historical, political, social and/or economic aspects involved.

In addition, new studies should be carried out in order to demonstrate, in our population, the consequences, advantages and disadvantages of such an important decrease in length of hospital stay for healthy newborns, especially in view of rehospitalization due to hyperbilirubinemia and low dietary intake, the main indicators used in the analysis of such protocols. ${ }^{13,14}$ Studies like the present one should contribute for the creation and review of health guidelines regarding hospital stay for healthy newborns. 


\section{References}

1. Braveman P, Egerter S, Pearl M, Marchi K, Miller C. Problems associated with early discharge of newborn infants. Early discharge of newborns and mothers: a critical review of the literature. Pediatrics. 1995;96:716-26.

2. Costa HP. Tempo de permanência hospitalar do recém-nascido. Correios SBP. 2003;9:10-11.

3. Brumfield CG, Nelson KG, Stotser D, Yarbaugh D, Patterson P, Sprayberry NK. 24-hour mother-infant discharge with a follow-up home health visit: results in a selected medicaid population. Obstet Gynecol. 1996;88:544-8.

4. Thilo EH, Townsend SF, Merenstein GB. The history of policy and practice related to the perinatal hospital stay. Clin Perinatol. $1998 ; 25: 257-70$.

5. Raube K, Merrell K. Maternal minimum-stay legislation: cost and policy implications. Am J Public Health. 1999;89:922-3.

6. Brasil. Ministério da Saúde. Portaria no. 1016 de 26 de Agosto de 1993. Normas básicas de Alojamento Conjunto. Diário Oficial da União. Brasília, 01 de Setembro de 1993. Of. no 1176/93.

7. Mariotoni GG, Barros Filho AA. Peso ao nascer e mortalidade hospitalar entre nascidos vivos, 1975-1996. Rev Saude Publica. 2000;34:71-6.

8. Scott A, Shiell A, Farnworth MG. The value of early discharge: dispelling some myths. Health Policy. 1993;26:81-91.

9. Centers for Disease Control and Prevention (CDC). Trends in length of stay for hospital deliveries--United States, 1970-1992. MMWR Morb Mortal Wkly Rep. 1995;44:335-7.
10. Wen SW, Liu S, Marcoux S, Fowler D. Trends and variations in length of hospital stay for childbirth in Canada. CMAJ. 1998;158: 875-80.

11. Farias LO, Melamed C. Segmentação de mercados da assistência à saúde no Brasil. Cienc Saude Coletiva. 2003;8:585-98.

12. Fundação Sistema Estadual de Análise de Dados (SEADE) [site na Internet]. Estatísticas vitais. Memórias das estatísticas demográficas. www.seade.gov.br/produtos/. Access: 28.07.2008.

13. Moura MB, Brenelli-Vitali MA, Marba ST. Reinternação no período neonatal de crianças nascidas saudáveis no Hospital Maternidade de Campinas. Rev Paul Pediatr. 2006;24:303-9.

14. Facchini FP, Mezzacappa MA, Rosa IR, Mezzacappa Filho F, Aranha-Netto A, Marba ST. Follow-up of neonatal jaundice in term and late premature newborns. J Pediatr (Rio J). 2007;83: 313-22.

Correspondence:

Mônica Barthelson Carvalho de Moura

Rua Santa Mônica, 389, casa 1 - Jd. Sta. Marcelina

CEP 13100-101 - Campinas, SP - Brazil

Tel.: + 55 (19) 3255.5862

Fax: +55 (19) 3236.2900

E-mail: monicabarthelson@terra.com.br 